\title{
GRUPO DE ESTUDOS E PESQUISA EM EDUCAÇÃO AMBIENTAL - GEPEASE
}

\author{
Maria Inêz Oliveira Araújo ${ }^{1}$
}

Resumo - O GEPEASE foi criado para dar apoio às atividades desenvolvidas pelo projeto Sala Verde na UFS. A princípio, o referido projeto teve como finalidade implementar a educação ambiental em uma perspectiva política em escolas de diferentes municípios sergipanos. Para tanto, com a intenção de transformar a inserção da dimensão ambiental no cotidiano da sala de aula, foram oferecidos cursos de formação ambiental para professores dos diferentes níveis escolares e disciplinas. Com a criação do GEPEASE, as ações se diversificaram e a sala verde passou a ser um espaço fomentador de interação e integração de ações em educação ambiental formal e não formal. Como exemplos temos as pesquisas Diagnóstico das Ações em Educação Ambiental no Estado de Sergipe e Implementação da Educação Ambiental Crítica com Freqüentadores da APA Morro do Urubu, um curso de especialização em educação ambiental para professores, finalizado com artigos, e outras pesquisas em contexto de monografias e dissertações de mestrado.

Palavras-chave: Educação ambiental, Formação de professores, Dimensão ambiental.

Abstract: The GEPEASE was created to support the activities developed by the Green Room project at the UFS. At first, this project was intended to implement environmental education in a political perspective in schools located in different cities in Sergipe. In order to do so, aiming to transform the inclusion of environmental dimension in the everyday classroom, environmental training courses were offered for teachers of different grade levels and disciplines. With the creation of the GEPEASE, actions have become diversified and the Green Room has turned into a place that promotes the interaction and integration of actions in formal and non-formal environmental education. Examples of these actions include the researches Diagnosis of Environmental Education Actions in the State of Sergipe and Implementation of Critical Environmental Education with Visitors of the Morro do Urubu Environmental Protection Area, a specialization course in environmental education for teachers, and other researches carried out in the form of monographs and dissertations.

Keywords: Environmental education, Teacher training, Environmental dimension.

1 ????????????????? 


\section{Introdução}

A partir de uma das ações do Ministério do Meio Ambiente foi criado o programa "Sala Verde", cuja proposta foi a implementação de espaços que constituam potenciais centros de informação e de Educação Ambiental no país, além do reforço às estruturas já existentes em diversas instituições.

Em 2005, a Universidade Federal de Sergipe, concorreu ao edital com o Projeto Sala Verde na UFS. Esse projeto atendendo aos propósitos do programa federal tem como finalidade democratizar o acesso às informações, materiais e publicações sobre questões ambientais e também oferecer atividades diversas voltadas à Educação Ambiental (cursos, palestras e oficinas), capaz de estimular a adoção de atitudes na busca de um ambiente sadio e socialmente justo.

Nessa direção, o projeto Sala Verde na UFS foi elaborado e está sendo executado com o propósito de desenvolver um projeto coletivo com e na comunidade que promova a construção da cidadania dos alunos, professores e comunidade do entorno das escolas, com vista para a sustentabilidade socioambiental. O grande desafio é introduzir no cotidiano de sala de aula atividades e concepções que levem os alunos a construir conhecimento acerca de sua localidade aliada ao desenvolvimento de uma nova maneira de se relacionar com o meio. Essa forma de pensar a educação e a prática pedagógica toma apoio nas leituras em Mauro Guimarães, Michele Sato, Marcos Reigota, Layrargues e outros.

A fim de dar suporte às ações da Sala Verde na UFS, assim como, incentivar a implementação da Educação Ambiental no Estado, foi criado o GRUPO DE ESTUDOS E PESQUISA EM EDUCAÇÃO AMBIENTAL GEPEASE, que vem se consolidando como espaço de estudo, construção de conhecimento e de saberes pedagógicos na UFS. Tem como objetivos:

a) Contribuir para fortalecimento das ações de pesquisa e aprofundamento teórico em educação ambiental;

b) Contribuir para a formação profissional de professores através de projetos de pesquisa; e

c) Socializar as vivências de ações em EA desenvolvidos na Sala Verde;

Um aspecto que contribui para o grupo desenvolver pesquisas e ações em educação ambiental, a qual recomenda que o estudo seja desenvolvido em caráter interdisciplinar, é a composição multidisciplinar de seus membros. O grupo está formado por alunos e professores de diferentes campos disciplinares (Pedagogia, Geografia, Turismo, Ciências Sociais, Engenharia Agronômica, Biologia, Filosofia e de profissionais de outras instituições de Ensino Superior e de uma ONG.) e tem como desafio efetivamente construir conhecimento sob procedimento metodológico apoiado na interdisciplinaridade, o que nos impõe muitas dificuldades. Concordo com Kralsichik e Pontuschka (2006), quando afirmam o "reconhecimento de culturas específicas de muitos dos grupos e a análise de sua origem e conseqüência para os paradigmas que orientam seus procedimentos são imprescindíveis no esforço para compreensão dos valores 
que estruturam esses grupos representativos de parcelas da comunidade científica".

Como sinalizam Japiassú e Jantsch e Bianchetti (1995), ainda não existe, no sentido epistemológico, um conceito unívoco e estável para interdisciplinaridade, mas trata-se de um conceito complexo que impõe dificuldades tanto na sua conceituação teórica, como para implementação de projetos e ação que visem a um conhecimento complexo dos objetos. As peculiaridades, presentes nos conceitos complexos envolvidos nessa perspectiva de interação disciplinar no ensino e na pesquisa, fazem da interdisciplinaridade um processo que enfrenta dificuldades e armadilhas que vão desde o âmbito epistemológico ao campo metodológico.

Por exemplo, a pesquisa sobre a implementação da educação ambiental crítica com frequentadores da APA Morro do Urubu - Parque da Cidade, realizada por bolsista do Programa de Iniciação Científica -PIBIC de diferente cursos (Artes, Engenharia Agronômica, Pedagogia e Biologia), tem como objetivo elaborar uma proposta que permita aos frequentadores da APA compreender a necessidade de desenvolver valores de co-responsabilidade com o meio.

Mesmo com a equipe multidisciplinar, é muito difícil realizar a pesquisa atendendo a interdisciplinaridade. Para Japiassú (1976), do ponto de vista epistemológico, as pesquisas interdisciplinares podem partir de duas preocupações fundamentais: uma, relativa às estruturas e aos mecanismos comuns às diferentes disciplinas científicas que são convidadas a se inserir no processo de interação ou colaboração, e a outra está relacionada aos possíveis métodos comuns a serem instaurados pelas disciplinas cooperantes.

Nesse sentido, o processo educativo busca contribuir para fortalecer a relação teoria-prática das ações educativas sob a perspectiva ambientalista. Os projetos realizados, e ainda em desenvolvimento, apresentam dois eixos de ação;

(1) contribuir para formação continuada dos professores, na crença de que os professores, quando bem orientados, se sentirão confortáveis em abordar as questões ambientais de sua localidade em sala de aula. Vale ressaltar que os cursos oferecidos aos professores se apóiam na prática da reflexão no sentido de preparálos para, no contexto de sala de aula, re-editar as informações e conhecimentos adquiridos durante o curso de formação e adequar a realidade do aluno;

(2) desenvolver ações que visem a aquisição de atitudes éticas de cidadania mediante a elevação da auto-estima em membros de uma comunidade que não tiveram acesso aos bens sociais, auxiliando professores e jovens da comunidade civil organizada a investirem em sua formação ambiental

Através das reflexões que deverão ser fomentadas no dia-a-dia seja na sala de aula ou em espaços de não formais, vislumbramos promover mudanças 
de postura e, conseqüentemente, mudanças de valores que até agora vêm sendo considerados como verdades absolutas e que a Escola atual insiste em preservar.

Como afirma Krasilchik (1986), a educação ambiental deverá servir não para transmitir conhecimento, mas também para desenvolver habilidades e atitudes que permitam ao homem atuar efetivamente no processo de manutenção de equilíbrio ambiental de modo a garantir uma qualidade de vida condizente com suas necessidades e aspirações.

Nessa perspectiva se faz mister que os professores tenham sua formação ambiental consolidada. Entendemos por formação ambiental a tomada de consciência do cidadão sobre o ambiente como forma de (des)naturalizar os agravos à saúde, ao bem-estar, à qualidade de vida, a degradação do ambiente e do ser humano decorrentes do mau uso dos bens naturais e exploração do humano historicamente instituídos. É necessário, para isso, elevar o cidadão à condição de agente transformador ao invés de continuarem atuando como meros expectadores da problemática que se instala. (ARAUJO, 2004). Por isso pensamos no projeto Formação Ambiental como Instrumento de Cidadania.

\section{Por que formação ambiental?}

As grandes transformações que o mundo vem passando exigem da comunidade uma nova mentalidade que transcenda a idéia da melhor valia que historicamente foi construída pela sociedade 'tecnológica' sob a luz do avanço e do progresso da industrialização que trouxe bastante arraigada a concepção da relação de sujeição, segundo Aurélio Buarque, ato de sujeitar, de criar dependência, submissão. Essa concepção, trazida pelo modelo de civilização imposta pela filosofia cartesiana, reconhece a natureza, e nela inclui-se o homem, como algo a ser dominado.

A história construiu com eficiência essa mentalidade e não deu oportunidade à população humana de perceber que estava cavando seu próprio fosso, o que pode ser evidenciado com os níveis de desigualdade social e junto a ela a violência, o incentivo ao consumismo, ao querer mais para ter mais poder.

Aos pouco foi sendo tirado do ser humano o direito a vida saudável. Concordo com Carvalho (1994), quando afirma que a luta pela satisfação das necessidades primárias, quase essencialmente biológica, não pode ser vista como dissociada da luta pelas liberdades de pensar, de opinar, de domar o próprio tempo, de fazer e escutar qualquer tipo de música e outras coisas essenciais ao ser humano da atualidade, porque o ser humano não é mais a primeira natureza, sujeito apenas às necessidades biológicas, mas é fundamentalmente um produtor de cultura que só vive em plenitude à custa de comida, de idéias e de liberdade para pensar, realizar e decidir. Uma cultura que reconheça os valores indissociáveis dos direitos humanos.

É com o desejo de contribuir para formação de pessoas consciente da sua responsabilidade com o ambiente que ele faz parte que nos apoiamos na abordagem da educação ambiental crítica/política para conduzir os projetos de 
extensão e pesquisa (CORCORAN (2001), SAUVÉ (1996, 2001), SORRENTINO (1995), ARAUJO (2004), LEFF(2000, 2001a, 1999)).

Portanto, que considere os aspectos socio-ambientais, na perspectiva de elevar o grau de conscientização sobre a problemática ambiental que nos constrange e nos ameaça com o alto índice de violência urbana, a prostituição infantil, o aumento da miséria e, em especial, a destruição dos bens naturais além de incutir uma nova mentalidade fundada em uma nova ética de relação com o meio.

\section{Projeto Pedagógico}

O trabalho é organizado em reuniões quinzenais que obedecem a seguinte estrutura:

a) Pedagógicas, que visam o aprofundamento teórico do grupo e definir a orientação teórica a ser seguida no curso de formação ambiental;

b) Administrativas que tratam das questões estruturais do grupo, da organização dos eventos acadêmicos e das questões de acompanhamento do Projeto Sala Verdes;

c) Orientações em grupo e individual que buscam contribuir com a pesquisa de bolsistas de iniciação científica, de mestrandos, e de graduandos.

Dessa forma, o grupo tem suas reflexões materializadas nas seguintes pesquisas:

\section{Doutorado:}

- Educação Biocêntrica e Alteridade como Acontecimento Ético:Uma vivência em educação Ambiental (UFBA) - trata-se de uma pesquisa de doutoramento que visa, mediante a vivência da biodança organizar o grupo gestor. Durante um ano, nas reuniões pedagógicas, a doutoranda Carla Coelho, desenvolveu a etapa empírica de sua pesquisa. Teve como referencial os princípios da Educação Biocêntrica, fundamentada teoricamente em Rolando Toro e metodologicamente em Carlos Brandão. A pesquisa encontra-se em fase de análise dos dados e elaboração do relatório final-tese.

\section{Mestrado:}

- Avaliação das Práticas desenvolvidas no Projeto Sala Verde na UFS pesquisa em andamento de abordagem qualitativa, que busca verificar a eficiência do projeto Sala Verde na mudança das práticas pedagógicas dos professores que participaram do curso de formação ambiental. Tem com referencial teórico a educação ambiental política construído a partir de leituras em Mauro Guimarães, Marcos Reigota, Mauro Grun, Loureiro, Adorno, Enrique Leff, Paulo Freire e outros. É um trabalho exploratório-descritivo onde sua coleta de dados será mediante questionário para eleger sua comunidade a ser pesquisa. 
- Educação Ambiental na Educação de Jovens e Adultos: estudo de caso em uma escola da rede estadual em Aracaju-SE

Nesse sentido, este trabalho apresenta um estudo de caso que procura discutir a relação entre a Educação Ambiental e a Educação de Jovens e Adultos a partir das concepções dos docentes do Centro de Referência em EJA Prof. Severino Uchôa, escola da rede estadual de ensino, em Aracaju-SE. A pesquisa busca analisar em que medida a dimensão ambiental perpassa as concepções dos professores sobre a Educação Ambiental e suas práticas na EJA. Considerando a natureza da pesquisa, optou-se pela abordagem metodológica qualitativa, tendo como instrumentos de coleta de dados a entrevista e o questionário direcionados aos professores de diversas áreas de ensino da Educação de Jovens e Adultos no segmento do ensino Médio (EJAEM) da referida escola. Busca-se, a partir daí, saber como os professores concebem a EJA e os seus objetivos e como se relacionam com essa modalidade de ensino, conhecendo também as dificuldades dos docentes no trabalho com esta modalidade de ensino. Além disso, objetiva-se ainda conhecer como os professores concebem a Educação, o Meio Ambiente, a Educação Ambiental e a Sustentabilidade, bem como a construção e o desenvolvimento das suas práticas em Educação Ambiental, colocando as possibilidades e os desafios dessa construção na escola.

- Educação ambiental nas escolas do campo: análise das concepções e práticas dos professores do sertão de vitória da conquista - ba.

A proposta dessa pesquisa é compreender como os professores que atuam na Educação do Campo de Vitória da Conquista compreendem a Educação Ambiental na sua ação pedagógica, a pesquisa se propõe discutir os desafios atuais da Educação assim utilizou-se autores como Santos (2008), Burbules e Torres (2004), Duarte (2008), Apple (2004) e Gentilli (2002) para compreender esses desafios atuais da educação, Ponthuscka (2007), Almeida (2006), e Araújo e Oliveira (2009) para compreender a formação de professores, para discutir a educação Ambiental numa perspectiva crítica tem se na pesquisa como autores, Loureiro (2007), Tozoni - Reis (2007), Guimarães (2005), Araújo (2007) e para discutir Educação do Campo procurou-se os seguintes autores Arroyo (2007) e Rocha e Martins (2009), Jesus (2004). Esta pesquisa é um estudo exploratório descritivo que busca compreender a contradição entre o que está proposto para a Educação Ambiental nas leis e o que está na prática das escolas do campo. Assim, investigar e refletir sobre quais as concepções dos educadores que executam a Educação Ambiental em escolas da zona rural que atuam com a modalidade da Educação do Campo.

- Práticas em educação ambiental no Colégio de Aplicação da UFSVerificar em que medida o tema transversal meio ambiente, ancorado numa dimensão de educação ambiental, está presente na prática e no 
discurso de professores de uma turma concluinte do ensino fundamental do Colégio de Aplicação da Universidade Federal de Sergipe. Terá suas análises sob a égide da vertente política da educação. Trata-se de um trabalho exploratório-descritivo, em que a coleta de dados será mediante pesquisa documental e entrevista.

\section{Iniciação Científica}

- Diagnóstico das Ações em Educação Ambiental no Estado de Sergipe, apoiado pelo PIBIC/CNPQ - teve como finalidade fazer um estudo sobre as abordagens teóricas que embasam as ações em educação ambiental no Estado. A fundamentação teórica oi construída a partir de leituras em Marcos Sorrentino, Michele Sato, Luiz Marcelo de

- Estudo de Viabilidade para implementacão da educacão ambiental no Parque da Cidade - APA Morro do Urubu- Se (PIBIC/COPES/FAPITEC) - visa implementar a educação ambiental com os frequentadores do Parque da Cidade e produção de material didático para frequentadores com deficiência visual e auditiva, nesse sentido, a pesquisa de abordagem qualitativa é desenvolvida mediante pesquisa participante.

Esses trabalhos de pesquisa são publicados em eventos acadêmicos locais e nacionais.

\section{Considerações}

O GEPEASE, mesmo com as dificuldades enfrentadas pela heterogeneidade do grupo, avança na produção científica e no trabalho de extensão, enfatizando o autoconhecimento sobre a educação ambiental como forma de transformação social mediante a construção de uma nova visão de mundo.

Referencias (parte da bibliografia utilizada nas diferentes pesquisas)

ARAÚJO, Maria Inêz $O$, A dimensão ambiental nos currículos de formação de professores de Bioliologia. Tese de doutorado defendida na Faculdade de Educação da Universidade de São Paulo, São Paulo, 2004

O. (a) A universidade e a formação de professores para a educação ambiental. In:

Revista Brasileira de Educação Ambiental/Rede Brasileira de Educação Ambiental. n.0 (nov. 2004), Brasília:REBEA, 2004. p.71-79.

BARCELOS, Valdo. Educação ambiental e antropofagia - uma contribuição à formação de professores. In: Revista Brasileira de Educação Ambiental/Rede Brasileira de Educação Ambiental. n.0 (nov. 2004), Brasília:REBEA, 2004. p. XX

BERRYMAN, T. Relieving modern day atlas of an illusory burden: abandoning the hypermodern fantasy of an education to manage the globe. Canadian Journal of Environmental Education, Canadá, v.4 p.50-68, 1999. 
CARNEIRO S. M. M. A Dimensão Ambiental da Educação Escolar de $1^{\mathrm{a}}-4^{\mathrm{a}}$ séries do ensino fundamental na rede escolar pública da cidade de Paranaguá. 1999. Tese (Curso de Doutorado em Meio Ambiente e Desenvolvimento) Universidade Federal do Paraná. Curitiba.

CARVALHO, I. C. M., A Invenção Ecológica: narrativas e trajetórias da educação ambiental no Brasil. Porto Alegre: Ed. Universidade/UFRS, 2001.

CARVALHO, L. M. de. Educação Ambiental e a Formação do Professores. In: Textos sobre Capacitação de Professores em Educação Ambiental. Coordenação Geral de Educação Ambiental. 2000. (mimeo).

CORCORAN, P. B.; SIEVERS, E. Reconceptualizing environmental education: five possibilities. The Journal Enviromental Education, Washington, v.28, n. 1, p 4-8, 1994. Enseñanza de las ciencias. v.19, n.2, p.309-318, 2001.

DIAS, G. F., Educação ambiental: princípios e práticas, 6aed.São Paulo: Gaia, 2000.

DIEGUES, A. C. S. O mito moderno da natureza intocada. $3^{a}$ ed. São Paulo: Hucitec/USP, 2000.

FOLADORI, G. Limites do desenvolvimento sustentável. Tradução de Marise Manoel, Campinas: Editora da Unicamp, São Paulo: Imprensa Oficial, 2001.

FREIRE, P. Conscientização: teoria e prática de libertação: uma introdução ao pensamento de Paulo Freire. Tradução de Kátia de Mello e Silva. $3^{a}$ ed. São Paulo: Moraes. 1980.

FREIRE, P.. Educação e mudança. Tradução de Moacir Gadotti e Lílian Lopes Martin. $21^{\circ}$ ed. Rio de Janeiro: Paz e Terra, 1979.

FREIRE, P.. Pedagogia do oprimido. $22^{\circ}$ ed. Rio de Janeiro: Paz e Terra, 1987.

GRÜN, M.. Ética e educação ambiental: a conexão necessária. Campinas: Papirus, 1996.

GUIMARÃES, Mauro. A dimensão ambiental na educação. Campinas: Papirus, 1995.

GUIMARÃES, Mauro. A formação de educadores ambientais, Campinas, SP: Papirus, 2004.

GUIMARÃES. Mauro. Educação ambiental: no consenso um embate? Campinas: Papirus, 2000.

KRASILCHIK, Myriam. Educação ambiental na escola brasileira - passado, presente e futuro. Ciência e Cultura, v. 38, n. 12, dez, 1986.

KRASILCHIK, Myriam; PONTUSCHKA, Nídia. N. Pesquisa Ambiental : construção de um processo participativo de educação e mudança, EDUSP : São Paulo, 2006.

LEFF, E. Saber ambiental: sustentabilidade, racionalidade, complexidade, poder. Tradução de Lúcia Mathilde Enddlich Orth. Petrópolis: Vozes, 2001. 
LEFF, Enrique.(a), Epistemologia Ambiental. Tradução de Sandra Valenzuela. São Paulo: Cortez, 2001.

LEFF, Enrique. Educação Ambiental e desenvolvimento sustentável. In: REIGOTA, M. (org) Verde Cotidiano: o meio ambiente em discussão. Rio de Janeiro: DP\&A, 1999.

LAYRARGUES, Philippe P. Educação ambiental com compromisso social: o desafio da superação das desigualdades. IN: LOUREIRO, Carlos F. B.; LAYRARGUES, Philippe P.; CASTRO, Ronaldo S. de, Repensar a educação ambienal: um olhar crítico, Cortez : São Paulo, 2009.

LOUREIRO, C.F. (org) A questão ambiental no pensamento crítico: natureza, trabalho e educação. Rio de Janeiro: Quartet, 2007.

.LOUREIRO, C. F. B. (Org) Sociedade e meio ambiente: a educação em debate. São Paulo: Cortez, 2000.

MATURANA R., H., VARELA G., F. A árvore do conhecimento: as bases biológicas do entendimento humano. Tradução de Jonas Pereira dos Santos, Campinas: Workshopsy, 1995.

MATURANA, H. O que se observa depende do observador. In: THOMPSON, W. I. (org.), Gaia: uma teoria do conhecimento. Tradução de Sílvio Cerqueira Leite, $3^{\mathrm{a}}$ ed. São Paulo: GAIA, 2001.

MINAYO, M. C. de S. Ciência, técnica e arte: o desafio da pesquisa social. In: Pesquisa social: teoria, método e criatividade. MINAYO, M. C. de S (Org) Petrópolis: Vozes, 1994.

MORIN, Edgar, Os setes saberes necessários à educação do futuro. Brasília: Cortez; UNESCO, 2000

PARDO DÍAZ, A. Educação ambiental como projeto. Tradução de Fátima Murad. $2^{a}$ ed., Porto Alegre: Artmed, 2002.

PONTUSCHKA, Nídia. N. A formação pedagógica do professor de Geografia e as práticas interdisciplinares. São Paulo, 1994. Tese (Doutorado em Educação) Faculdade de Educação da Universidade de São Paulo.

QUINTAS, J. S. Por uma educação emancipatória: considerações sobre a formação do educador para atuar no processo de gestão ambiental. In: QUINTAS, J. S. (Org.) Pensando e praticando a educação ambiental na gestão do meio ambiente. Brasília: IBAMA, 2000.

REIGOTA, M. Meio ambiente e representação social. $5^{\mathrm{a}}$ ed. São Paulo: Cortez, 2002. REIGOTA, M. O que é educação ambiental. São Paulo: Cortez, 1998.

RUSCHEINKY, A.. COSTA, A.. L. A educação ambiental a partir de Paulo Freire..In: RUSCHEINKY, A.(Org.) Educação Ambiental: abordagens múltiplas. Porto Alegre: Artmed, 2002. 
SACHS, Ignacy. Estratégias de transição para o século XXI: desenvolvimento e meio ambiente. São Paulo: Studio Nobel e Fundação de Desenvolvimento Administrativo (FUNDAP), 1993.

SANTOS, Boaventura de S. Um discurso sobre as ciências. São Paulo: Cortez, 2003.

SATO, M. Apaixonadamente pesquisadora em educação ambiental. Educação: Teoria e Prática, Rio Claro, v. 19 n. 16. jan-jun e nº 17 , jul-dez, p.24-35, 2001.

SATO, Michèle. Formação em educação ambiental - da escola à comunidade. In: COEA/MEC (org.) Panorama da Educação Ambiental no Brasil. Brasília: MEC, março de 2000, p. 5-13.

SAUVÉ, L. Environmental education and sustainable development: a further appraisal. Canadian Journal of Environmental Education, Canadá, v.1, p. 7-34, 1996.

2002.

Environmental education: possibilities and constraint. Connect, v. XXVII, p 1-4,

SEVERINO, A J. A relevância social e a consistência epistêmica da pesquisa em educação: alguns subsídios para se avaliar a pesquisa em educação ambiental. Educação:teoria e prática. Rio Claro V. 9 n 16, e no 17, p.10-16, 2001.

SEVERINO, A. J. Metodologia do trabalho científico. 23. ed. rev. e atualizada. - São Paulo: Cortez, 2007.

SOARES, M. J. Nascimento. Teoria e prática: uma articulação na experiência do exercício da docência nas series iniciais na rede pública de ensino. In: ARAUJO, M. I. O. et all, Desafios da formação de professores para o século XXI: A construção do novo olhar sobre a prática docente. São Cristovão: Editora UFS, 2009.

SORRENTINO, M. Educação ambiental e universidade: um estudo de caso. São Paulo, 1995. Tese (Doutorado em Educação) - Programa de Pós-Graduação em Educação da Universidade de São Paulo.

Artigo recebido em 20/08/2010 - aprovado em 17/12/2010 